\title{
On the Rate of Interaction of Sodium Borohydride with Platinum (IV) Chloride Complexes in Alkaline Media
}

\author{
Magdalena Luty-Błocho ${ }^{1, *(\mathbb{D})}$, Marek Wojnicki ${ }^{1}$, Edit Csapo ${ }^{2,3}{ }^{\mathbb{D}}$ and Krzysztof Fitzner ${ }^{1}$ \\ 1 Faculty of Non-Ferrous Metals, AGH University of Science and Technology, Al. A. Mickiewicza 30, \\ 30-059 Krakow, Poland; marekw@agh.edu.pl (M.W.); fitzner@agh.edu.pl (K.F.) \\ 2 Department of Physical Chemistry and Materials Science, University of Szeged, Rerrich B. Sqr. 1, \\ 6720 Szeged, Hungary; juhaszne.csapo.edit@med.u-szeged.hu \\ 3 MTA-SZTE Biomimetic Systems Research Group, Department of Medical Chemistry, Faculty of Medicine, \\ University of Szeged, Dóm Sqr. 8, 6720 Szeged, Hungary \\ * Correspondence: mlb@agh.edu.pl; Tel.: +48-12-617-4126
}

check for updates

Citation: Luty-Błocho, M.; Wojnicki, M.; Csapo, E.; Fitzner, K. On the Rate of Interaction of Sodium Borohydride with Platinum (IV) Chloride Complexes in Alkaline Media. Materials 2021, 14, 3137. https:// doi.org/10.3390/ma14113137

Academic Editor: Adam Cwudziński

Received: 28 April 2021

Accepted: 3 June 2021

Published: 7 June 2021

Publisher's Note: MDPI stays neutral with regard to jurisdictional claims in published maps and institutional affiliations.

Copyright: (C) 2021 by the authors Licensee MDPI, Basel, Switzerland. This article is an open access article distributed under the terms and conditions of the Creative Commons Attribution (CC BY) license (https:/ / creativecommons.org/licenses/by/ $4.0 /)$.

\begin{abstract}
In this work, sodium borohydride was used as a strong reductant of traces of platinum complex ions. The investigations of the kinetics of redox reaction between platinum(IV) chloride complex ions and sodium borohydride were carried out. For the first time, the kinetic experiments were carried out in a basic medium ( $\mathrm{pH}$ 13), which prevents $\mathrm{NaBH}_{4}$ from decomposition and suppresses the release of hydrogen to the environment. The rate constants of $\mathrm{Pt}(\mathrm{IV})$ reduction to $\mathrm{Pt}(\mathrm{II})$ ions under different temperatures and concentrations of chloride ions conditions were determined. In alkaline solution ( $\mathrm{pH} 13$ ), the values of enthalpy and entropy of activation are $29.6 \mathrm{~kJ} / \mathrm{mol}$ and $-131 \mathrm{~J} / \mathrm{mol} \mathrm{K}$. It was also found that oxygen dissolved in the solution strongly affects kinetics of the reduction process. Using collected results, the reduction mechanism was suggested. For the first time, the appearance of diborane as an intermediate product during $\mathrm{Pt}(\mathrm{IV})$ ions reduction was suggested. Moreover, the influence of oxygen present in the reacting solution on the rate of reduction reaction was also shown.
\end{abstract}

Keywords: chloride Pt(IV) complex ions; sodium borohydride; chemical reduction; diborane; zeroorder reaction

\section{Introduction}

One of the most important topics for the past two decades has been the recovery of so-called strategic metals (e.g., platinum group metals, rare earths) accompanied with the production of environmentally friendly waste. It is due to the increase of public awareness and in response to environmental derelicts (for example, Directive 2006/21/EC on the management of waste from extractive industries and amending Directive 2004/35/EC), as well as implementation of UE strategy for raw materials (https:/ / eur-lex.europa.eu/legal-content/EN/TXT/?uri=CELEX:52011DC0025 (accessed on 10 May 2021)). These regulations stimulate the demand for new technologies which will allow effective metal recovery and purification of waste solution. Among metals, platinum is important due to many potential applications in catalysis [1], modern chemistry, medicine [2], and engineering. For platinum recovery, several techniques can be used such as extraction [3], leaching [4], sorption [5], precipitation [6], chemical reduction, and biological methods [7]. However, despite the high level of recovery, the methods mentioned above do not guarantee environmentally friendly waste. There are at least two reasons why it happens. The first is directly related to the recovery process itself, which requires the use of hazardous reagents. Such a substance may penetrate into the waste solution as an unreacted reagent or as a hazardous product of the reaction. The second is related to the form of recovered metals. Especially, metals at nanoscale may be dangerous for life and difficult to recover. They are just toxic and difficult to remove simply by filtration. 
In this context, we suggest using sodium borohydride as a strong reductant of platinum ions. It is known that $\mathrm{NaBH}_{4}$ is hazardous, but as a result of the reaction with metal precursor it can be neutralized to an environmentally ambient form such as boric acid, borax. These compounds are used as food additives [8]. Moreover, the high efficiency of $\mathrm{NaBH}_{4}$ requires an application of a small amount of this reductant. The use of sodium borohydride as a reductant allows for a fast reduction of metal ions and nuclei formation. It in turn promotes the formation of small homogeneous nanoparticles (1-3 nm in diameter) which can be used in any field of science [9-11]. The high efficiency of sodium borohydride and thus its strong reducing property depends strongly on the $\mathrm{pH}$ of the reacting solution. It has been already confirmed in the literature [12] that its reducing activity increases with the increasing concentration of $\mathrm{H}_{3} \mathrm{O}^{+}$ions in the solution. This fact is related to the rate of decomposition of $\mathrm{NaBH}_{4}$ in water, which accelerates visibly below $\mathrm{pH}=9.24$. In an aqueous solution, $\mathrm{NaBH}_{4}$ dissociates according to the reaction:

$$
\mathrm{NaBH}_{4} \leftrightarrow \mathrm{Na}^{+}+\mathrm{BH}_{4}^{-}
$$

and in the presence of water, $\mathrm{BH}_{4}^{-}$hydrolyzes spontaneously [13]:

$$
\mathrm{BH}_{4}^{-}+4 \mathrm{H}_{2} \mathrm{O} \leftrightarrow \mathrm{B}(\mathrm{OH})_{4}^{-}+4 \mathrm{H}_{2}
$$

In the course of this reaction, hydrogen evolves rapidly.

Taking into account reactions of hydrolysis of sodium borohydride and the hexachloroplatinate (IV) [13-15], the process of reduction reaction of $\mathrm{Pt}(\mathrm{IV})$ ions was investigated under alkaline conditions, which assures the presence of $\mathrm{BH}_{4}^{-}$as the reductant in the solution, as well as $\left[\mathrm{PtCl}_{5}(\mathrm{OH})\right]^{2-}$ ions as the metal precursor. Consequently, the reduction process between $\mathrm{Pt}(\mathrm{IV})$ ions and $\mathrm{NaBH}_{4}$ in alkaline solution $(\mathrm{pH} \sim 13)$ in the simplest form can be described by the reaction:

$$
\left[\mathrm{PtCl}_{5}(\mathrm{OH})\right]^{2-}+\mathrm{BH}_{4}^{-} \stackrel{k_{1}}{\rightarrow} \text { products }
$$

where $k_{1}$ denotes the rate constant of reaction (3).

The possible product of this reaction can be either $\mathrm{Pt}(\mathrm{II})$ complex or metallic platinum particles. Many studies indicate that the process of nanoparticles formation is fast. However, nobody measured the rate of the processes preceding it, i.e., the reduction of $\mathrm{Pt}(\mathrm{IV})$ to $\mathrm{Pt}(\mathrm{II})$ ions and next $\mathrm{Pt}(\mathrm{II})$ to $\mathrm{Pt}(0)$. Moreover, there is no reliable model which can describe these stages. In order to follow how sodium borohydride behaves during the reaction with $\mathrm{Pt}(\mathrm{IV})$ ions, we decided to undertake a detailed study of the first step in the process of platinum particles formation, i.e., reduction of $\mathrm{Pt}(\mathrm{IV})$ to $\mathrm{Pt}(\mathrm{II})$ ions. Moreover, based on the obtained kinetic data, the possible mechanism of PtNPs formation will be suggested. The choice of the experimental conditions was related to the elimination of possible processes that could run parallel to the reduction of $\mathrm{Pt}(\mathrm{IV})$ ions with sodium borohydride.

\section{Materials and Methods}

\subsection{Chemicals}

The base solution of platinum precursor, i.e., $0.076 \mathrm{M}$ solution of $\mathrm{H}_{2} \mathrm{PtCl}_{6}$ was obtained from the metallic platinum with purity $99.99 \%$ (Mennica-Metale Szlachetne, Radzymin, Poland). For this purpose, the metallic platinum was dissolved in aqua regia (mixture of $36 \% \mathrm{HCl}$ and $65 \%$ nitric acid in volumetric ratio 3:1, p.a. Chemland, Stargard Szczeciński, Poland) solution, which was dried four times to remove an excess of nitric acid and at the end in hydrochloride acid to keep the acidic $\mathrm{pH}$ of the solution. Before every experiment, the fresh solution of $\mathrm{Pt}(\mathrm{IV})$ ions was prepared, then the proper volume of base solution was diluted in deionized water. The proper reducer concentration was obtained by dissolving the powder of sodium borohydride $\left(\mathrm{NaBH}_{4}, 96 \%\right.$, Fluka, Loughborough, UK) into $0.1 \mathrm{M}$ solution of $\mathrm{NaOH}$ (p.a. Chemland, Stargard Szczeciński, Poland), which kept the $\mathrm{pH}$ alkaline $(\sim 13)$ and prevented it from a degradation of $\mathrm{NaBH}_{4}$ [16-18]. In the case of 
experiments performed in deaerated solutions, the water and sodium hydroxide solutions were purged with nitrogen for $30 \mathrm{~min}$.

\subsection{Methods}

In the experiments, the redox reaction was monitored at a fixed wavelength $(262 \mathrm{~nm})$ using the stopped-flow spectrophotometer (Applied Photophysics, Leatherhead, UK) working in the UV-Vis range (from 190-900 nm wavelength) with the $1-\mathrm{cm}$ or $0.2-\mathrm{cm}$ optical path. The spectrum of the $\left[\mathrm{PtCl}_{6}\right]^{2-}$ solution in $0.05 \mathrm{M} \mathrm{NaOH}$ was recorded to establish the fixed wavelength of $262 \mathrm{~nm}$ used as a reference to monitor concentration changes. However, due to the stability diagram (Figure S1, Supplementary materials) this reference refers in fact to $\left[\mathrm{PtCl}_{5}(\mathrm{OH})\right]^{2-}$ species. All kinetic curves, which include about one hundred data points each, were repeated six times to obtain each value of the observed rate constant $\left(k_{1, \mathrm{obs}}\right)$.

\subsection{Dynamic Light Scattering (DLS)}

In order to determine the presence of a solid phase in the aqueous solution and particles size, the DLS method was applied (Nano Zeta-S, Malvern, UK).

\section{Results}

\subsection{Experimental Conditions}

The conditions of the conducted experiments are gathered in Table 1.

Table 1. Conditions of experiments for the reaction between platinum(IV) chloride complex ions and sodium borohydride. Conditions: $\mathrm{pH}=12.9 \pm 0.2$, ionic strength $\mathrm{I}=0.05 \mathrm{M}$ (except, chloride addition).

\begin{tabular}{|c|c|c|}
\hline Initial Concentration of Reagents, $\mathbf{M}$ & Temperature, $\mathrm{K}$ & $\mathrm{NaCl}$ Addition, $\mathrm{M}$ \\
\hline \multicolumn{3}{|c|}{ The stoichiometry of reaction } \\
\hline $\mathrm{C}_{0, \mathrm{Pt}(\mathrm{IV})}: \mathrm{C}_{0, \mathrm{NaBH} 4}$ & - & - \\
\hline $1: 2$ & 298 & - \\
\hline $1: 1$ & - & - \\
\hline $2: 1$ & - & - \\
\hline $3: 1$ & - & - \\
\hline- & Effect of temperature & - \\
\hline 0.053 .0 & 288 & - \\
\hline- & 298 & - \\
\hline- & 308 & - \\
\hline- & 318 & - \\
\hline \multicolumn{3}{|c|}{ Effect of $\mathrm{Cl}^{-}$concentration (at constant value of ionic strength $\mathrm{I}=0.4 \mathrm{M}$ and $\left[\mathrm{Na}^{+}\right]=0.4 \mathrm{M}$ ) } \\
\hline 0.053 .0 & 298 & 0.05 \\
\hline- & - & 0.10 \\
\hline- & - & 0.20 \\
\hline- & - & 0.30 \\
\hline- & - & 0.40 \\
\hline
\end{tabular}

\subsection{Spectra of Reagents and Pt(IV) Complex Ions Stability}

The aqueous solution of $\mathrm{Pt}(\mathrm{IV})$ complex ions exhibits a strong absorption band in the UV region with maximum at the wavelength $(\lambda) 262 \mathrm{~nm}$ (Figure 1a). The localization of the maximum intensity may change depending on the hydrolysis progress (details described by subsequent reactions and stability diagram (Equations (1)-(4), Figure S1, Supplementary Materials). In order to check the spectrum stability, different media were also tested, and the results are given (Figure 1a and Figure S2, Supplementary Materials). It is known, that $\mathrm{Pt}(\mathrm{IV})$ complex ions are very stable in comparison to gold(III) and palladium(II) chloride ions. The platinum(IV) complex is more stable in hydrochloric acid and in the solution with the addition of sodium chloride (Figure S2b,c, Supplementary Materials) 
compared to the water and solution of sodium chlorate (Figure S2a,d,e, Supplementary Materials), which could be expected. For the medium such as water, hydrochloric acid, sodium chloride, sodium chlorate, and sodium hydroxide there is no visible difference between spectra obtained for freshly prepared Pt(IV) solutions. In all these cases, the position of the maximum was located at $262 \mathrm{~nm}$ with a small difference in absorbance intensity. However, such results do not prove the presence of the same form of $\mathrm{Pt}(\mathrm{IV})$ ions. Murray et al. [18] and Cox et al. [19] observed the same location of spectrum maxima for species such as $\left[\mathrm{PtCl}_{5}\left(\mathrm{H}_{2} \mathrm{O}\right)\right]^{-}$and $\left[\mathrm{PtCl}_{6}\right]^{2-}$, and the same value of molar coefficient at $353 \mathrm{~nm}\left(\varepsilon_{353 \mathrm{~nm}}=490 \mathrm{M}^{-1} \mathrm{~cm}^{-1}\right)$. However, the value of molar coefficient at $262 \mathrm{~nm}$ was different and equals $11600 \mathrm{M}^{-1} \mathrm{~cm}^{-1}$ for $\left[\mathrm{PtCl}_{5}\left(\mathrm{H}_{2} \mathrm{O}\right)\right]^{-}$and $24500 \mathrm{M}^{-1} \mathrm{~cm}^{-1}$ for $\left[\mathrm{PtCl}_{6}\right]^{2-}$. Taking into account the observation by Cox et al. [19], it can be expected that the formed alkaline solution $\left[\mathrm{PtCl}_{5}(\mathrm{OH})\right]^{2-}$ complex (stability diagram in Figure S1b, Supplementary Materials) can also change the value of the molar coefficient. For this purpose, at first, the aqueous solution of $\left[\mathrm{PtCl}_{6}\right]^{2-}$ was obtained by a dissolution of a proper volume of base solution in the deionized water (concentration $0.1 \mathrm{mM}$ ) in order to assure $\left[\mathrm{PtCl}_{5}\left(\mathrm{H}_{2} \mathrm{O}\right)\right]^{-}$formation. Then, it was immediately mixed in volumetric ratio (1:1) with $0.1 \mathrm{M}$ solution of $\mathrm{NaOH}$. The obtained spectra were gathered (Figure S3a, Supplementary Materials). Based on them, the value of molar coefficient was determined at $262 \mathrm{~nm}$ $\left(\varepsilon_{262 \mathrm{~nm}}=29307 \pm 650 \mathrm{M}^{-1} \mathrm{~cm}^{-1}\right)$ (Figure S3b, Supplementary Materials). To be sure, we also checked if the prepared solution reached equilibrium (Equation (3), Supplementary Materials). For this purpose, the spectrum for $\mathrm{Pt}(\mathrm{IV}$ ) ions in $0.05 \mathrm{M} \mathrm{NaOH}$ (mixed as previously, i.e., aqueous solution of $\mathrm{Pt}(\mathrm{IV})$ ions with $0.1 \mathrm{M} \mathrm{NaOH}$, at volumetric ratio 1:1) were recorded for $2 \mathrm{~h}$ (Figure 1a). Small changes in absorbance value in time (Figure 1a') are related to the fluctuation of measured values. This confirms that the equilibrium has been reached and $\left[\mathrm{PtCl}_{5}(\mathrm{OH})\right]^{2-}$ was formed (Equation (3), Supplementary Materials). It is worth noting that for the experiment in which a proper volume of base solution $(0.076 \mathrm{M})$ of $\mathrm{Pt}(\mathrm{IV})$ ions was mixed directly with $10 \mathrm{~mL}$ of $0.05 \mathrm{M} \mathrm{NaOH}$, the spectrum with much higher intensity was registered (Figure S4a, Supplementary Materials), and the value of molar coefficient was also established $\left(\varepsilon_{262 \mathrm{~nm}}=(34709 \pm 742) \mathrm{M}^{-1} \mathrm{~cm}^{-1}\right.$ (Figure S4b). Moreover, for such a prepared solution, the small decrease in the maximum at $262 \mathrm{~nm}$ was observed after $30 \mathrm{~min}$ (Figure S5, Supplementary Materials). This result suggests that the equilibrium has not be reached in the considered time or the time needed for conversion of one form into another is much longer (Equation (4), Supplementary Materials). Moreover, what happened with the solution of $\mathrm{Pt}(\mathrm{IV})$ complex was tested in different media with time. The UV-Vis spectra registered one month later showed changes in spectrum character, intensity, and maximum location. These changes can be attributed with further hydrolysis process (Figure S2a-e, Supplementary Materials).

Since the reduction reaction of platinum(IV) ions with sodium borohydride takes about $30 \mathrm{~s}$, and overall processes leading to PtNPs formation only $60 \mathrm{~s}$ (Figure 1b), we are sure that in the case of hydrolysis reaction of $\left[\mathrm{PtCl}_{6}\right]^{2-}$ and rapid deprotonation of its product, in practice reduction takes place mainly between $\left[\mathrm{PtCl}_{5}(\mathrm{OH})\right]^{2-}$ complex and $\mathrm{BH}_{4}{ }^{-}$ions.

After mixing of the reactants (volume ratio 1:1), the decrease of absorbance for platinum(IV) chloride complex ions in time was observed (Figure 2a). Due to the LambertBeer's Law, this change is due to a decrease of reactant concentration. It shows that the redox reaction (3) between $\left[\mathrm{PtCl}_{5}(\mathrm{OH})\right]^{2-}$ and $\mathrm{BH}_{4}{ }^{-}$takes place. Moreover, during the reaction between $\mathrm{Pt}(\mathrm{IV})$ ions and sodium borohydride, two isosbestic points were detected on the UV-Vis spectrum (Figure 2a). The first one is located at the wavelength $219 \pm 1 \mathrm{~nm}$, while the second one at $237 \pm 1 \mathrm{~nm}$. A similar value of the wavelength was observed in our previous work [5]. It can be also noted, that with the decreasing maximum value of absorbance at $262 \mathrm{~nm}$ (decreasing concentration of $\mathrm{Pt}(\mathrm{IV})$ ions), we observed a simultaneously increasing value of absorbance at $233 \mathrm{~nm}$, which can be associated with the formation of $\mathrm{Pt}(\mathrm{II})$ ions in the solution. It is compatible with the results of Gammons et al. [20] and Wojnicki et al. [5]. The disappearing peak associated with Pt(IV) ions and the visible change 
in the absorbance at lower wavelength indicate that the reduction reaction which takes place is:

$$
\left[\mathrm{PtCl}_{5}(\mathrm{OH})\right]^{2-}+\mathrm{BH}_{4}^{-} \stackrel{k_{1}}{\rightarrow} \mathrm{Pt}(\mathrm{II})+\text { products }
$$

and as a result of this reaction, $\mathrm{Pt}(\mathrm{IV})$ ions are reduced to $\mathrm{Pt}(\mathrm{II})$ ions.

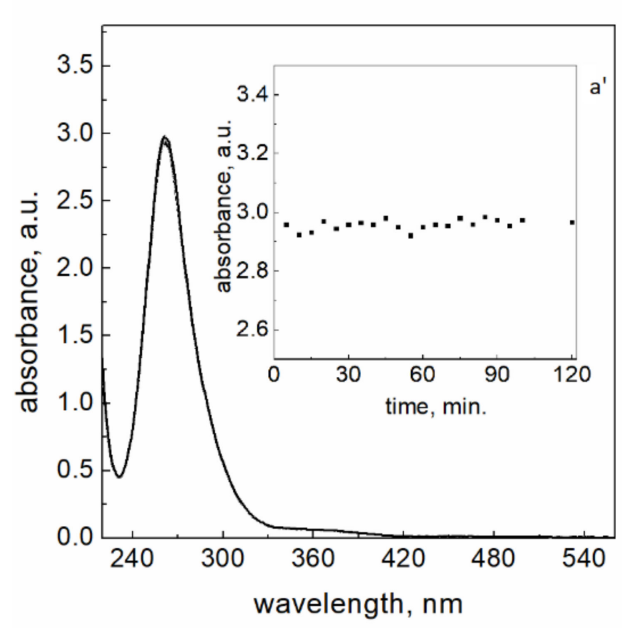

(a)

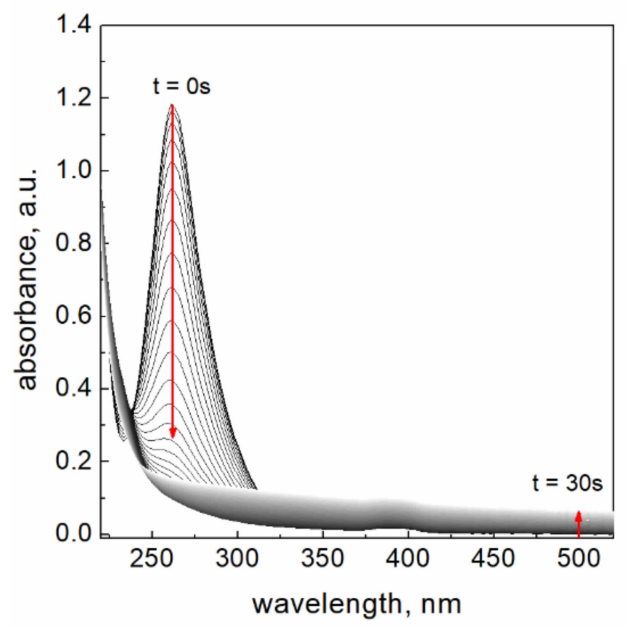

(b)

Figure 1. (a) Spectrum of aqueous solutions containing $5 \cdot 10^{-4} \mathrm{M} \mathrm{Pt}(\mathrm{IV})$ complex ions in $0.05 \mathrm{M} \mathrm{NaOH}$; kinetic curve for $\mathrm{Pt}(\mathrm{IV})$ in $0.05 \mathrm{M} \mathrm{NaOH}$ registered at $262 \mathrm{~nm}\left(\mathbf{a}^{\prime}\right)$. Optical path length $2 \mathrm{~mm}$; (b) change of absorption bands characteristic for $\mathrm{Pt}(\mathrm{IV})$ complex ions during the reaction with $\mathrm{NaBH}_{4}$. Conditions: $\mathrm{C}_{0, \mathrm{Pt}(\mathrm{IV})}=0.05 \mathrm{mM}, \mathrm{C}_{0, \mathrm{NaBH}}=3.0 \mathrm{mM}, \mathrm{I}=0.05 \mathrm{M}$, $\mathrm{T}=50.0 \pm 0.1^{\circ} \mathrm{C}, \mathrm{pH}=12.9 \pm 0.2$, path length $1 \mathrm{~cm}$.

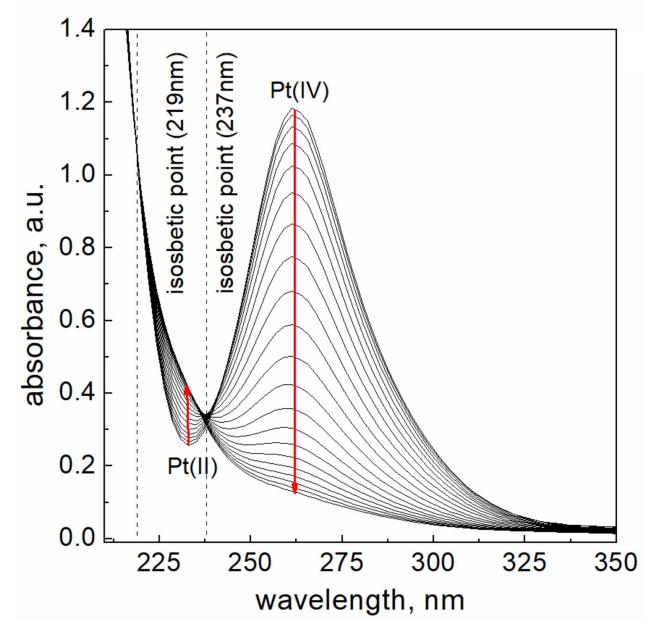

(a)

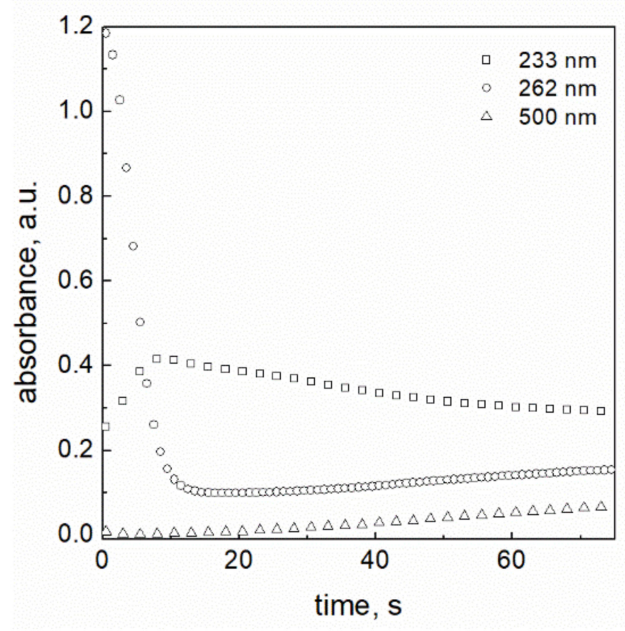

(b)

Figure 2. (a) Change of absorption bands characteristic for $\mathrm{Pt}(\mathrm{IV})$ complex ions during the reaction with $\mathrm{NaBH}_{4}$. Conditions: $\mathrm{C}_{0, \mathrm{Pt}(\mathrm{IV})}=0.05 \mathrm{mM}, \mathrm{C}_{0, \mathrm{NaBH} 4}=3.0 \mathrm{mM}, \mathrm{I}=0.05 \mathrm{M}, \mathrm{T}=50.0 \pm 0.1{ }^{\circ} \mathrm{C}, \mathrm{pH}=12.9 \pm 0.2$. Time of reaction $10 \mathrm{~s}$ (with step $0.2 \mathrm{~s}$ ); (b) the change of absorbance value (A $\propto$ concentration of Pt species) with time (kinetic curves) during the reaction of platinum ions with $\mathrm{NaBH}_{4}$. Conditions: $\mathrm{C}_{0, \mathrm{Pt}(\mathrm{IV})}=0.05 \mathrm{mM}, \mathrm{C}_{0, \mathrm{NaBH}}=3.0 \mathrm{mM}, \mathrm{I}=0.05 \mathrm{M}, \mathrm{T}=50.0 \pm 0.1^{\circ} \mathrm{C}$, $\mathrm{pH}=12.9 \pm 0.2$, path length $1 \mathrm{~cm}$.

It is also observed, that after about $4 \mathrm{~s}$, the further decrease of absorbance in the whole considered range was registered. Then, after next $10 \mathrm{~s}$, an increase of absorbance level in the range of wavelength from 250 to $550 \mathrm{~nm}$ (Figure 1b) is observed, and it is associated with the appearance in the solution metallic platinum of nanometric size. It was confirmed experimentally with the DLS method, which detected particles of nanometric $(4.4 \pm 1.4 \mathrm{~nm}$ 
in hydrodynamic radius, Figure S6 Supplementary Materials) size (2 min after mixing of reagents). It is worth noting that the formed particles are unstable and continue to grow up to $44 \pm 20 \mathrm{~nm}$ (10 min after mixing of reagents) (Figure S7, Supplementary Materials).

Considering the registered absorbance at 262,233, and $500 \mathrm{~nm}$ (value established for the recording of turbidity level in the solution, see details in Figure S8, Supplementary Materials) with time (Figure 2b), we can depict its change for all stages of the reduction reaction. However, it must be underlined that using the spectrophotometric method only the changes of $\mathrm{Pt}(\mathrm{IV})$ ions concentration with time can be followed. Nevertheless, one can imagine also the relative changes of concentrations of $\mathrm{Pt}(\mathrm{II})$ and $\mathrm{Pt}(0)$ with time, which let us divide the whole process into three stages.

Consequently, taking all these facts into account, a possible mechanism of reduction reaction can be suggested:

I-st stage, reduction reaction of $\mathrm{Pt}(\mathrm{IV})$ ions to $\mathrm{Pt}(\mathrm{II})$ in accordance with the following scheme:

$$
\mathrm{Pt}(\mathrm{IV}) \stackrel{k_{1, \mathrm{obs}}}{\rightarrow} \mathrm{Pt}(\mathrm{II})
$$

II-nd stage is responsible for the reduction reaction of $\mathrm{Pt}(\mathrm{II})$ ions to $\mathrm{Pt}(0)$, i.e., it is the nucleation process:

$$
\mathrm{Pt}(\mathrm{II}) \stackrel{k_{2, \mathrm{obs}}}{\rightarrow} \mathrm{Pt}(0)
$$

III-rd stage, describing autocatalytic growth, is typical for noble metals nanoparticles formation [21-27]:

$$
\mathrm{Pt}(\mathrm{II})+\mathrm{Pt}(0) \stackrel{k_{3, \text { obs }}}{\rightarrow} 2 \mathrm{Pt}(0)
$$

where $k_{1, \mathrm{obs}}, k_{2, \mathrm{obs}}, k_{3, \mathrm{obs}}$ denote the observed rate constants in Equations (5)-(7).

With the experimental technique used in this work, only the first stage of this suggested mechanism, i.e., the rate of reaction (5) can be investigated.

\subsection{The Stoichiometry of Reduction Reaction of Pt(IV) Using Sodium Borohydride}

The stoichiometry of reduction reaction of $\mathrm{Pt}(\mathrm{IV})$ ions using sodium borohydride was determined under a different molar ratio of reagents (Table S1, Supplementary Materials). The concentration change was followed by spectrophotometric observation of the rate of disappearance of the platinum(IV) ions at wavelength $262 \mathrm{~nm}$ until its total reduction (absorbance tends to 0 ). The minimum on the graph (Figure S9, Supplementary Materials) showing the dependence of absorbance on the molar ratio $\mathrm{C}_{0, \mathrm{NaBH}}: \mathrm{C}_{0, \mathrm{Pt}(\mathrm{IV})}$ appeared at 2:1 ratio. This means that the reaction of chloride $\mathrm{Pt}(\mathrm{IV})$ ions with $\mathrm{NaBH}_{4}$ runs in the following proportions:

$$
\left[\mathrm{PtCl}_{5}(\mathrm{OH})\right]^{2-}+2 \mathrm{BH}_{4}^{-} \stackrel{k_{1}}{\rightarrow} \mathrm{Pt}(\mathrm{II})+\text { products }
$$

\subsection{Determination of the Rate Constants}

The rate constants of the reduction reaction of $\mathrm{Pt}(\mathrm{IV})$ ions with sodium borohydride were established using the equation fitted to the experimental data recorded at the wavelength $262 \mathrm{~nm}$. The obtained kinetic curves registered at different temperatures and the sample of fitted kinetic curve to the obtained data are given in Figure 3. 


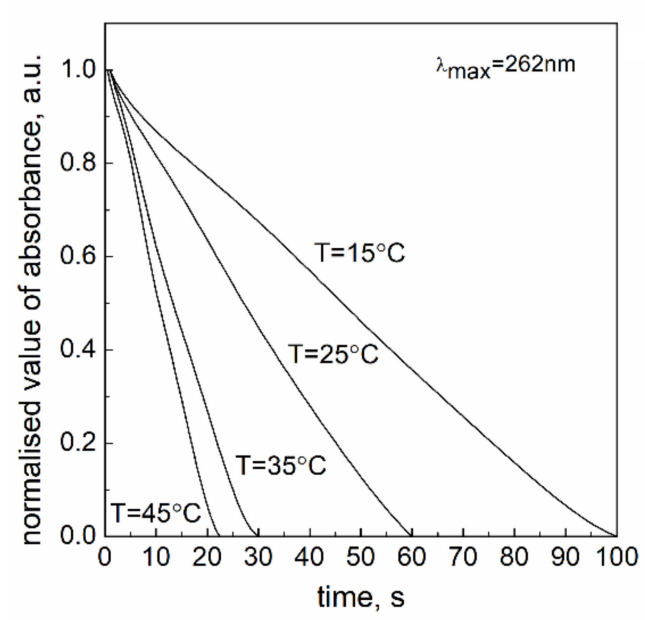

(a)

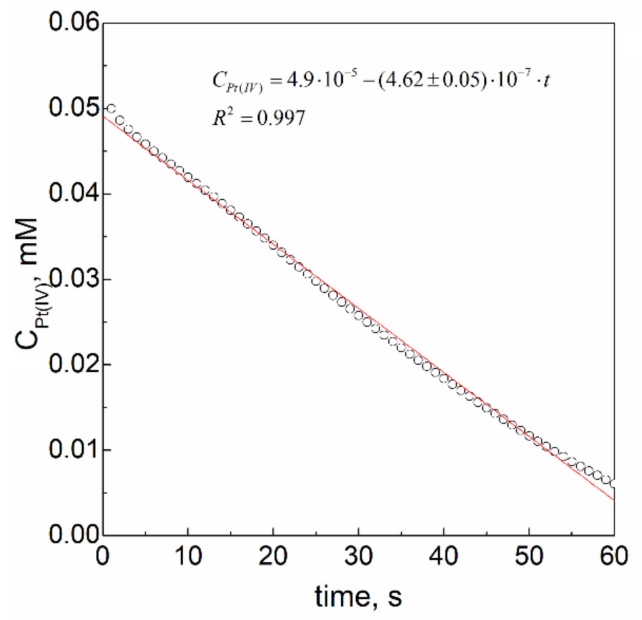

(b)

Figure 3. (a) The kinetic curves obtained at $262 \mathrm{~nm}$ for the reaction between platinum(IV) chloride complex ions and sodium borohydride in aqueous solution at different temperatures; (b) the sample of kinetic curve (change of $\mathrm{Pt}(\mathrm{IV})$ ions concentration in time of reaction reduction) at $25^{\circ} \mathrm{C}(\mathbf{b})$. Conditions: $\mathrm{C}_{0, \mathrm{Pt}(\mathrm{IV})}=0.05 \mathrm{mM}, \mathrm{C}_{0, \mathrm{NaBH} 4}=3.0 \mathrm{mM}, \mathrm{pH}=12.9 \pm 0.2$.

The character of these curves is linear and it suggests that the process of reduction of metal ions (Equation (5)) is zero-order. For such a process, the differential equation has the form:

$$
-\frac{\mathrm{d} A_{P t(I V)}}{\mathrm{d} t}=k_{1, o b s}
$$

Taking into account that the value of absorbance is proportional to $\mathrm{Pt}(\mathrm{IV})$ ions concentration ( $\left.\mathrm{A} \propto C_{P t(I V)}\right)$, Equation (9) has the following form:

$$
-\frac{\mathrm{d}\left(C_{\left.P t(I V) \times \varepsilon_{262 n m} \times l\right)}\right.}{\mathrm{d} t}=k_{1, o b s}
$$

where $\varepsilon_{262}$ denotes the molar absorption coefficient for Pt(IV) ions $\left(\varepsilon_{262 \mathrm{~nm}}=29307 \pm 499 \mathrm{M}^{-1} \mathrm{~cm}^{-1}\right.$ and $l$-path length $(l=1 \mathrm{~cm})$.

Under isolation conditions $\left(C_{\mathrm{NaBH}_{4}} \gg C_{P t(I V)}\right)$, the reaction between platinum(IV) chloride complex ions and sodium borohydride is assumed to be a pseudo zero-order, where the observed rate constant is in fact expressed as:

$$
k_{1, o b s}=k_{1} \times \mathrm{C}_{\mathrm{NaBH}_{4}}
$$

Values of $k_{1, \mathrm{obs}}$ from the experiments and calculated values of $k_{1}$ Equation (11) are gathered in Table 2.

Table 2. Values of the pseudo zero-order and zero-order rate constants for redox reaction of platinum(IV) chloride complex ions with sodium borohydride obtained at different temperatures. Conditions: $\mathrm{C}_{0, \mathrm{Pt}(\mathrm{IV})}=0.05 \mathrm{mM}, \mathrm{C}_{0, \mathrm{NaBH}}=3.0 \mathrm{mM}, \mathrm{pH}=12.9 \pm 0.2$.

\begin{tabular}{ccc}
\hline Temperature, $\mathbf{K}$ & $\begin{array}{c}\boldsymbol{k}_{\mathbf{1 , \mathbf { o b s }} \mathbf{1 0}} \mathbf{1 0}^{\mathbf{3}} \\
\mathbf{M s}^{-\mathbf{1}}\end{array}$ & $\begin{array}{c}\boldsymbol{k}_{\mathbf{1}} \cdot \mathbf{1 0} \\
\mathbf{s}^{-\mathbf{1}}\end{array}$ \\
\hline 288 & $10.82 \pm 0.18$ & $36.08 \pm 0.59$ \\
298 & $13.55 \pm 0.07$ & $45.17 \pm 0.22$ \\
308 & $28.24 \pm 0.24$ & $94.13 \pm 0.79$ \\
318 & $37.36 \pm 0.22$ & $124.54 \pm 0.74$ \\
\hline
\end{tabular}




\subsection{Effect of Temperature}

For determination of the parameters in the Eyring equation, the values of observed rate constants ( $\left.k_{1, \mathrm{obs}}\right)$ of reaction (5) were determined. The obtained values of $k_{1, \mathrm{obs}}$, and $k_{1}$ (zero-order rate) are gathered in Table 2 . The obtained results show that the value of $k_{1}$ increases with the increasing temperature. From the linear equation of modified Eyring relationship [28]:

$$
T \times \ln \frac{k_{1}}{T}=\left(\ln \frac{k_{B}}{h}+\frac{\Delta S^{\neq}}{R}\right) \times T-\frac{\Delta H^{\neq}}{R}
$$

where $k_{1}$ is the zero-order rate constant; $T$ is the temperature in $\mathrm{K}$; $R$ is the gas constant; $k_{\mathrm{B}}$ is the Boltzmann constant; $h$ is Planck's constant; $\Delta S^{\neq}$is the entropy of activation; and $\Delta H^{\neq}$ is the enthalpy of activation.

The values of the enthalpy $\left(\Delta H^{\neq}=29.6 \mp 2.6 \mathrm{~kJ} \cdot \mathrm{mol}^{-1}\right)$ and the entropy $\left(\Delta S^{\neq}=-131 \mathrm{~J} \cdot \mathrm{K}^{-1} \mathrm{~mol}^{-1}\right)$ of activation were calculated by applying the graphical method (Figure 4).

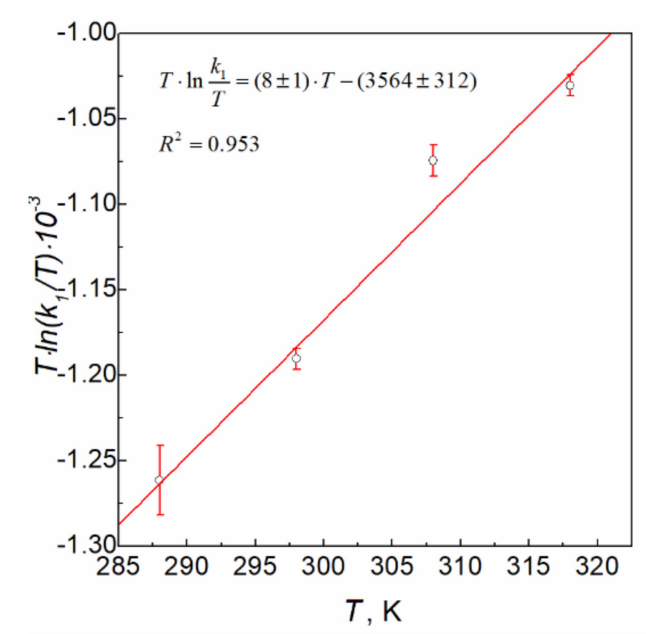

Figure 4. The linear plot of Eyring dependence $\left(T \cdot \ln \left(k_{1} / T\right)\right.$ vs. $\left.T\right)$ for the reaction between platinum(IV) chloride complex ions and sodium borohydride in aqueous solution. Conditions: $\mathrm{C}_{0, \mathrm{Pt}(\mathrm{IV})}=0.05 \mathrm{mM}, \mathrm{C}_{0, \mathrm{NaBH} 4}=3.0 \mathrm{mM}, \mathrm{pH}=12.9 \pm 0.2$.

It is worth noting that the process of sodium borohydride decomposition is also dependent on the temperature [13], in which the rise accelerates this reaction. For example, for temperature $288 \mathrm{~K}$, the half time of sodium borohydride decomposition is $283 \mathrm{~h}$, and at $318 \mathrm{~K}$ it takes only $27 \mathrm{~h}$ [13]. Still, this time is much longer than the time of the experiment and this process can be neglected.

\subsection{Effect of Chloride Ions}

In order to check the influence of chloride ions $\left(\mathrm{Cl}^{-}\right)$addition on the rate constant, different initial concentrations of $\mathrm{Cl}^{-}$ions in the solution were used. The obtained results are gathered in Table 3. 
Table 3. Values of the observed pseudo-zero- and zero-order rate constants (average of six independent kinetic experiments) for the reaction between platinum(IV) chloride complex ions and sodium borohydride at different $\mathrm{Cl}^{-}$concentrations. Conditions: $\mathrm{C}_{0, \mathrm{Pt}(\mathrm{IV})}=0.05 \mathrm{mM}, \mathrm{C}_{0, \mathrm{NaBH} 4}=3.0 \mathrm{mM}$, $\mathrm{T}=25.0 \pm 0.1{ }^{\circ} \mathrm{C}, \mathrm{pH}=12.9 \pm 0.2,\left[\mathrm{Na}^{+}\right]=0.4 \mathrm{M}, \mathrm{I}=0.4 \mathrm{M}$.

\begin{tabular}{ccc}
\hline$\left[\mathbf{C l}^{-}\right], \mathbf{M}$ & $\boldsymbol{k}_{\mathbf{1}, \mathbf{o b s}} \mathbf{1 0}^{\mathbf{2}}, \mathbf{M s}^{-\mathbf{1}}$ & $\boldsymbol{k}_{\mathbf{1}}, \mathbf{s}^{\mathbf{- 1}}$ \\
\hline 0.00 & $14.36 \pm 0.73$ & $47.88 \pm 2.43$ \\
0.05 & $16.12 \pm 0.89$ & $53.74 \pm 2.96$ \\
0.15 & $20.30 \pm 1.35$ & $67.69 \pm 4.50$ \\
0.25 & $28.39 \pm 0.96$ & $94.64 \pm 3.21$ \\
0.35 & $31.78 \pm 1.17$ & $105.93 \pm 3.90$ \\
\hline
\end{tabular}

It can be seen that the values of $k_{1, \text { obs }}$ increase with an increase of $\mathrm{Cl}^{-}$ions concentration in the reacting solution. The plot of the observed rate constant vs. the initial $\mathrm{Cl}^{-}$ concentration is linear and shown in Figure 5.

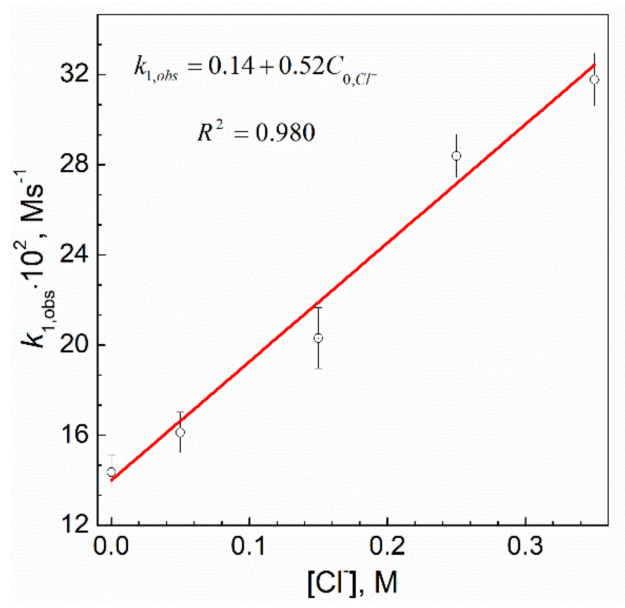

Figure 5. The influence of chloride ions addition on the observed rate constant for the reaction between platinum(IV) ions and sodium borohydride. Conditions: $\mathrm{C}_{0, \mathrm{Pt}(\mathrm{IV})}=0.05 \mathrm{mM}, \mathrm{C}_{0, \mathrm{NaBH} 4}=3.0 \mathrm{mM}$, $\mathrm{T}=25.0 \pm 0.1{ }^{\circ} \mathrm{C}, \mathrm{pH}=12.9 \pm 0.2$.

Fitting the linear equation to these results, the functional dependency of $k_{1, \mathrm{obs}}$ on the initial concentration of $\mathrm{Cl}^{-}$ions takes the following form:

$$
k_{1, o b s}=0.14+0.52 C_{0, l^{-}}
$$

It is worth noting that during the reduction reaction of $\mathrm{Pt}(\mathrm{IV})$ ions with sodium borohydride carried out under the conditions described in Table 1 (i.e., at different additions of chloride ions), no visible change in the reacting mixture was observed. In order to explain the observed influence of chloride ions on the reaction rate, two experiments with a much bigger amount of $\mathrm{NaCl}$ were carried out. In the first test, the powder of about $0.1 \mathrm{~g}$ of sodium chloride was added to the solution with sodium borohydride. In order to enhance the potential effect, the mixture of reductant and salt was not stirred. After a few seconds, at the batch bottom (not diluted salt yet) small bubbles of gas appeared. The second test was performed on the mixture of metal ions with a reductant and addition of $\mathrm{NaCl}$ (about $0.1 \mathrm{~g})$. Immediately after the salt addition, the gaseous bubbles appeared in the solution. The intensity of gas evolution was much higher than in the case of the first experiment. These experiments confirmed that the sodium chloride addition enhances the process of sodium borohydride hydrolysis, which is accelerated when metallic platinum is present in the solution. Our results are contrary to those of Gupta et al. [29], who found that the addition of $\mathrm{Cl}^{-}$ions to the reaction mixture inhibits the rate. 


\subsection{The Role of Oxygen}

It is surprising that our studies showed a zero-order reaction for the reduction with sodium borohydride. Therefore, one can think about the reason of such a dependence. However, usually experiments of this type are carried out in the laboratory under air (standard procedure). It is known from the literature, that oxygen plays an important role in the electron-transfer process [30]. A simple molecule can be used as either a catalyst or an inhibitor of the back electron transfer reaction. In order to explain the mechanism of $\mathrm{Pt}(\mathrm{IV})$ ions reduction with sodium borohydride for which the obtained kinetic curves are linear, the role of oxygen was studied. For this purpose, the deaerated solution of water and sodium hydroxide was used. The obtained kinetic curves are given in Figure 6.

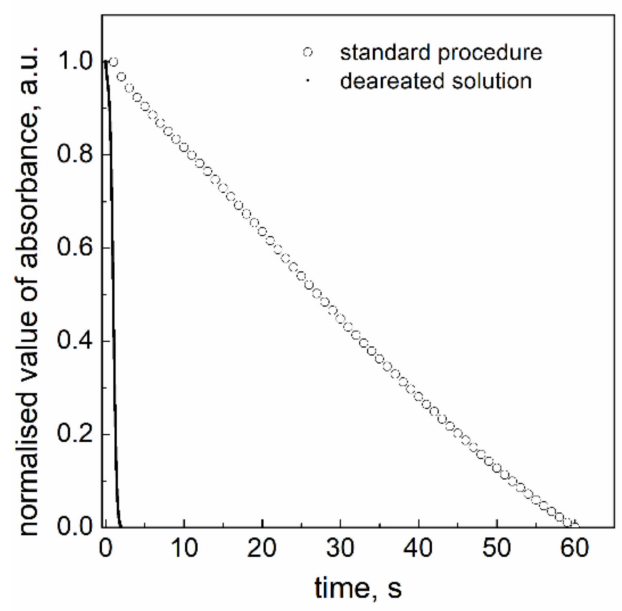

(a)

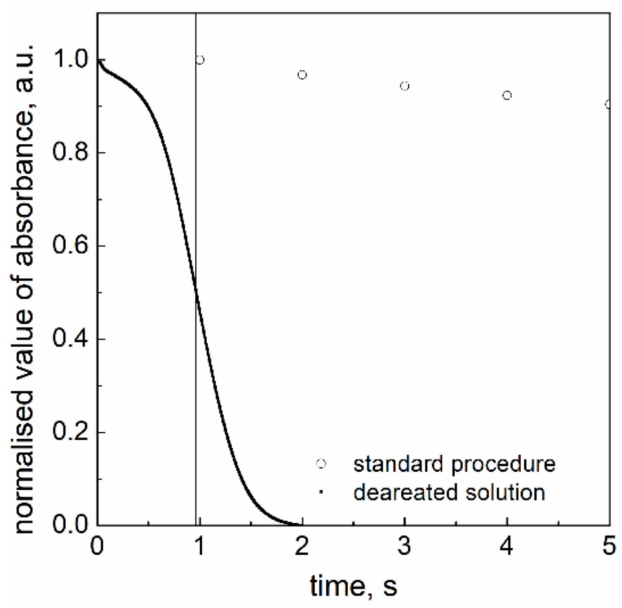

(b)

Figure 6. (a) Kinetic curves obtained for the reaction between platinum(IV) chloride complex ions and sodium borohydride at a standard procedure and in the case of deaerated solution; (b) kinetic curves registered in a short time. Conditions: $\mathrm{C}_{0, \mathrm{Pt}(\mathrm{IV})}=0.05 \mathrm{mM}, \mathrm{C}_{0, \mathrm{NaBH} 4}=3.0 \mathrm{mM}, \mathrm{T}=25.0 \pm 0.1^{\circ} \mathrm{C}, \mathrm{pH}=12.9 \pm 0.2$.

The character of observed kinetic curves for solutions saturated with oxygen and deaerated one is different. The process runs much faster if oxygen has been removed. The kinetic curve registered for the deaerated solution demonstrates that the $\mathrm{Pt}(\mathrm{IV})$ ions reduction consists of at least two steps. The first is slow and the second is fast, maybe also catalytic. Based on this observation, we assumed that oxygen dissolved in the reacting mixture strongly affects the overall process rate. This also confirms that in the case of a standard procedure (solution under air with dissolved oxygen), the oxygen plays the role of the inhibitor.

\section{Discussion}

The sodium borohydride was found to be an efficient reductant of platinum(IV) chloride ions in alkaline ( $\mathrm{pH}$ about 13) solutions. The reduction reaction of $\mathrm{Pt}(\mathrm{IV})$ ions to $\mathrm{Pt}(\mathrm{II})$ is fast, and pseudo zero-order. The integral form of kinetic equation describing the concentration change of platinum(IV) complex ions with time have the following form:

$$
C_{P t(I V)}=C_{0, P t(I V)}-\frac{k_{1, o b s}}{\varepsilon_{262 n m} \times l} \times t
$$


Experimental rate constants are sensitive to the temperature. Considering Eyring's parameters determined in our experiments, the empirical dependence of $k_{1}=\mathrm{f}(T)$ has the following form:

$$
k_{1}=\frac{k_{B} \times T}{h} \exp \left(\frac{T\left(-131 \mathrm{JK}^{-1} \mathrm{~mol}^{-1}\right)-29.6 \mathrm{kJmol}^{-1}}{R T}\right)
$$

A negative value for $\Delta S^{\neq}$indicates that entropy decreases during formation of the transition state. It can result from the associative mechanism in which two reacting species form a single activated complex. Moreover, the addition of chloride ions accelerates the reaction of $\mathrm{Pt}(\mathrm{IV})$ ions with sodium borohydride. On the one hand, such a behavior is unexpected taking into account the fact, that the addition of $\mathrm{Cl}^{-}$ions affects strongly the stability of the chloride complex. On the other hand, the addition of $\mathrm{NaCl}$ to the reductant accelerates the process of $\mathrm{NaBH}_{4}$ decomposition. As a result, hydrogen appears, which may also act as a strong reductant.

The reaction is complex and has at least two stages, i.e., the reduction of $\mathrm{Pt}(\mathrm{IV})$ ions to $\mathrm{Pt}(\mathrm{II})$ and the reduction of $\mathrm{Pt}(\mathrm{II})$ to the metallic state $\mathrm{Pt}(0)$. As a result of autocatalytic growth (stage III), platinum nanoparticles are formed with a hydrodynamic radius $44 \pm 20 \mathrm{~nm}$ (10 min after mixing of reagents). The following mechanism of the PtNPs formation can be proposed. Due to hexachloroplatinate (IV) hydrolysis [14] followed by rapid deprotonation of the aqua-complexes, reaction (16) takes place:

$$
\left[\mathrm{PtCl}_{5}\left(\mathrm{H}_{2} \mathrm{O}\right)\right]^{-} \stackrel{K}{\Leftrightarrow}\left[\mathrm{PtCl}_{5}(\mathrm{OH})\right]^{2-}+\mathrm{H}^{+} \rightarrow
$$

where $K$ denotes the equilibrium constant. Under experimental conditions, the equilibrium of this reaction is shifted strongly to the right (Figure S1b, Supplementary Materials). The formed hydrolyzed species can be next reduced in the following chain of reactions:

I stage:

$$
\left[\mathrm{PtCl}_{5}(\mathrm{OH})\right]^{2-}+2 \mathrm{BH}_{4}^{-} \stackrel{k_{1}}{\rightarrow}\left[\mathrm{PtCl}_{3}(\mathrm{OH})\right]^{2-}+2 \mathrm{Cl}^{-}+\mathrm{B}_{2} \mathrm{H}_{6}+\mathrm{H}_{2}
$$

II stage:

$$
\left[\mathrm{PtCl}_{3}(\mathrm{OH})\right]^{2-}+2 \mathrm{BH}_{4}^{-} \stackrel{k_{2}}{\rightarrow} \mathrm{Pt}+\mathrm{B}_{2} \mathrm{H}_{6}+\mathrm{H}_{2}+3 \mathrm{Cl}^{-}+\mathrm{OH}^{-}
$$

III stage:

$$
\left[\mathrm{PtCl}_{3}(\mathrm{OH})\right]^{2-}+2 \mathrm{BH}_{4}^{-}+\mathrm{Pt} \stackrel{k_{3}}{\rightarrow} 2 \mathrm{Pt}+\mathrm{B}_{2} \mathrm{H}_{6}+\mathrm{H}_{2}+3 \mathrm{Cl}^{-}+\mathrm{OH}^{-}
$$

where $k_{i}(i=1-3)$ denote the rate constants for reactions (17-19) and consequently reverses the reaction of reduction.

It can be suggested that during the course of reactions (17-19) an intermediated, short-lived product in the form of diborane $\left(\mathrm{B}_{2} \mathrm{H}_{6}\right)$ is formed. This kind of intermediate was suggested by Pourzahedi and Eckelman [31] during the reduction of silver ions with $\mathrm{NaBH}_{4}$. Moreover, Long discussed possible forms of diborane intermediates in alkaline solutions (Long, 1974). In our case it must be unstable [32], and under basic conditions it should react very rapidly with the hydroxyl group according to the following reaction:

$$
2 \mathrm{~B}_{2} \mathrm{H}_{6}+4 \mathrm{OH}^{-} \rightarrow 3 \mathrm{BH}_{4}^{-}+\left[\mathrm{B}(\mathrm{OH})_{4}\right]^{-}
$$

Moreover, the results of this work indicate a huge influence of oxygen dissolved in the solution on the kinetics of redox reaction between $\mathrm{Pt}(\mathrm{IV})$ ions and sodium borohydride. The 
process of metal ions reduction proceeds much faster in the deaerated aqueous solution. Taking into account that oxygen may oxidize the product of reaction (17), it yields:

$$
2\left[\mathrm{PtCl}_{3}(\mathrm{OH})\right]^{2-}+\mathrm{O}_{2}+4 \mathrm{Cl}^{-}+4 \mathrm{H}_{3} \mathrm{O}^{+} \stackrel{k_{4}}{\rightarrow} 2\left[\mathrm{PtCl}_{5}(\mathrm{OH})\right]^{2-}+6 \mathrm{H}_{2} \mathrm{O}
$$

where $k_{4}$ denotes the rate constant in Equation (21).

This reaction pattern can be supported by the following thermodynamic argument. Taking into account the reaction of $\mathrm{Pt}(\mathrm{II})$ with oxygen in the form:

$$
2\left[\mathrm{PtCl}_{4}\right]^{2-}+\mathrm{O}_{2}+4 \mathrm{Cl}^{-}+4 \mathrm{H}_{3} \mathrm{O}^{+} \stackrel{k_{5}}{\rightarrow} 2\left[\mathrm{PtCl}_{6}\right]^{2-}+6 \mathrm{H}_{2} \mathrm{O}
$$

where $k_{5}$ denotes the rate constant in Equation (22), all thermodynamic parameters for this reaction are known [33], and $\Delta G^{\circ}$ (calculated with the Outotec HSC 7 Chemistry software) of this reaction is equal to $-192 \mathrm{~kJ}$ at $298 \mathrm{~K}$. As it can be seen, this reaction should be spontaneous, and it can be treated as irreversible. One can assume, that reaction (21) exhibits a negative value of $\Delta G^{\circ}$, and it has to also be spontaneous.

\section{Conclusions}

Summarizing the results of this work one can conclude that:

a. The reduction reaction between $\mathrm{NaBH}_{4}$ and $\left[\mathrm{PtCl}_{5}(\mathrm{OH})\right]^{2-}$ complex ions can be imagined as a three-stage process:

$$
\mathrm{Pt}(\mathrm{IV}) \rightarrow \mathrm{Pt}(\mathrm{II}) \rightarrow \mathrm{Pt}(0) \rightarrow \mathrm{PtNPs}
$$

b. Spectrophotometric experiments gave the rate constants of the first stage yielding values of the pseudo-zero order and zero-order rate constants as a function of temperature.

c. The obtained values of the enthalpy $\Delta H^{\neq}$and entropy $\Delta S^{\neq}$of activation are $29.6 \pm 2.6 \mathrm{~kJ} / \mathrm{mol}$ and $-131 \mathrm{~J} / \mathrm{mol} \cdot \mathrm{K}$, respectively.

d. Sodium chloride addition (an increase of $\mathrm{Cl}^{-}$ions concentration) enhances the rate of reaction.

e. The reduction process is much faster in the deaerated solution. It means that the dissolved oxygen acts as the inhibitor of redox reaction.

Supplementary Materials: The following are available online at https:/ /www.mdpi.com/article/ 10.3390/ma14113137/s1. Figure S1: Stability diagram for Pt(IV) complex ions depending on the initial concentration of chloride ions (a) and $\mathrm{pH}$ of the solution (b). Conditions: $\mathrm{C}_{0, \mathrm{Pt}(\mathrm{IV})}=0.05 \mathrm{mM}$, $\left[\mathrm{Cl}^{-}\right]=0.3 \mathrm{mM}, \mathrm{T}=25.0 \pm 0.1^{\circ} \mathrm{C}$; Figure S2: Spectra of Pt(IV) ions at different media: $\mathrm{H} 2 \mathrm{O}$ (a), $0.1 \mathrm{M} \mathrm{HCl}$ (b), $0.1 \mathrm{M} \mathrm{NaCl}$ (c), $0.1 \mathrm{M} \mathrm{NaClO} 4$ (d), $\mathrm{NaOH}$ (e). Conditions: $\mathrm{C}_{0, \mathrm{Pt}(\mathrm{IV})}=0.5 \mathrm{mM}$, $\mathrm{T}=25.0 \pm 0.1^{\circ} \mathrm{C}$, path length $2 \mathrm{~mm}$; Figure S3: Spectra of Pt(IV) ions in $0.05 \mathrm{M} \mathrm{NaOH}(\mathrm{a})$; dependency of maximum value of absorbance registered at $262 \mathrm{~nm}$ vs. initial concentration of $\mathrm{Pt}(\mathrm{IV})$ ions (b). Conditions: $\mathrm{C}_{0, \mathrm{Pt}(\mathrm{IV})}=0.16 \cdot 10-5 \mathrm{M}-0.05 \mathrm{mM}, \mathrm{T}=25.0 \pm 0.1^{\circ} \mathrm{C}$, path length $1 \mathrm{~cm}$; Figure S4: Spectra of $\mathrm{Pt}(\mathrm{IV})$ ions in $0.05 \mathrm{M} \mathrm{NaOH}(\mathrm{a})$; dependency of maximum value of absorbance registered at $262 \mathrm{~nm}$ vs. initial concentration of $\mathrm{Pt}(\mathrm{IV})$ ions (b). Conditions: $\mathrm{C}_{0, \mathrm{Pt}(\mathrm{IV})}=0.16 \cdot 10-5 \mathrm{M}-0.05 \mathrm{mM}, \mathrm{T}=25.0 \pm 0.1^{\circ} \mathrm{C}$, path length 1cm; Figure S5: Spectra of Pt(IV) ions in $0.05 \mathrm{M} \mathrm{NaOH}$. Black line-Route I, grey lineRoute II. Conditions: $\mathrm{C}_{0, \mathrm{Pt}(\mathrm{IV})}=0.05 \mathrm{mM}, \mathrm{T}=25.0 \pm 0.1{ }^{\circ} \mathrm{C}$, path length $1 \mathrm{~cm}$; Figure S6: Size distribution of PtNPs by number ( 2 min after mixing of reagents). Conditions: $\mathrm{C}_{0, \mathrm{Pt}(\mathrm{IV})}=0.05 \mathrm{mM}$, $\mathrm{C}_{0, \mathrm{NaBH}}=3.0 \mathrm{mM}, \mathrm{T}=25.0 \pm 0.1{ }^{\circ} \mathrm{C}$, path length $1 \mathrm{~cm}$; Figure S7: Size distribution of PtNPs by number (10 min after mixing of reagents). Conditions: $\mathrm{C}_{0, \mathrm{Pt}(\mathrm{IV})}=0.05 \mathrm{mM}, \mathrm{C}_{0, \mathrm{NaBH}}=3.0 \mathrm{mM}$, $\mathrm{T}=25.0 \pm 0.1^{\circ} \mathrm{C}$, path length $1 \mathrm{~cm}$; Figure S8: The change of absorbance value with time registered at $500 \mathrm{~nm}$. Conditions: $\mathrm{C}_{0, \mathrm{Pt}(\mathrm{IV})}=0.05 \mathrm{mM}, \mathrm{C}_{0, \mathrm{NaBH} 4}=3.0 \mathrm{mM}, \mathrm{I}=0.05 \mathrm{M}, \mathrm{T}=25.0 \pm 0.1^{\circ} \mathrm{C}$; Figure S9: Graph of the dependence of absorbance as the function $\mathrm{C}_{0, \mathrm{NaBH}}: \mathrm{C}_{0, \mathrm{Pt}(\mathrm{IV})}$. Conditions: Different initial concentrations of reagents, $\mathrm{pH}=12.9 \pm 0.2, \mathrm{~T}=298 \pm 0.1 \mathrm{~K}, \mathrm{I}=0.05 \mathrm{M}$; Table S1: The experimental conditions for determination of reduction reaction stoichiometry. 
Author Contributions: Conceptualization, M.L.-B. and M.W.; methodology, M.L.-B.; validation, E.C.; formal analysis, M.L.-B. and M.W.; investigation, M.L.-B.; writing—original draft preparation, M.L.-B.; writing-review and editing, E.C. and K.F.; supervision, K.F. Percentage share of co-authors: M.L.-B. (50\%), M.W. (30\%), E.C. (10\%), and K.F. (10\%). All authors have read and agreed to the published version of the manuscript.

Funding: This research was funded by the European Grant No. POIG.01.01.02-00-015/09-00 and was supported by the Polish Ministry of Science and Higher Education under subvention funds for the Faculty of Non-Ferrous Metals and by program "Excellence Initiative-Research University" for the University of Science and Technology.

Institutional Review Board Statement: Not applicable.

Informed Consent Statement: Not applicable.

Data Availability Statement: Additional results are contained in Supplementary Material.

Conflicts of Interest: The authors declare no conflict of interest.

\section{References}

1. Kettler, P.B. Platinum Group Metals in Catalysis: Fabrication of Catalysts and Catalyst Precursors. Org. Process Res. Dev. 2003, 7, 342-354. [CrossRef]

2. Jeyaraj, M.; Gurunathan, S.; Qasim, M.; Kang, M.-H.; Kim, J.-H. A Comprehensive Review on the Synthesis, Characterization, and Biomedical Application of Platinum Nanoparticles. Nanomaterials 2019, 9, 1719. [CrossRef]

3. Rane, M.V. PGM ore processing: LIX reagents for palladium extraction \& platinum stripping from Alamine $336 \mathrm{using} \mathrm{NaOH}-\mathrm{NaCl}$. Miner. Eng. 2019, 138, 119-124.

4. Jha, M.; Lee, J.-C.; Kim, M.-S.; Jeong, J.; Kim, B.-S.; Kumar, V. Hydrometallurgical recovery/recycling of platinum by the leaching of spent catalysts: A review. Hydrometallurgy 2013, 133, 23-32. [CrossRef]

5. Wojnicki, M.; Socha, R.P.; Luty-Błocho, M.; Fitzner, K. Kinetic studies of the removal of Pt(IV) chloride complex ions from acidic aqueous solutions using activated carbon. React. Kinet. Mech. Catal. 2017, 120, 715-734. [CrossRef]

6. Schreier, G.; Edtmaier, C. Separation of Ir, Pd and Rh from secondary Pt scrap by precipitation and calcination. Hydrometallurgy 2003, 68, 69-75. [CrossRef]

7. Hedrich, S.; Kraemer, D.; Junge, M.; Marbler, H.; Bau, M.; Schippers, A. Bioprocessing of oxidized platinum group element (PGE) ores as pre-treatment for efficient chemical extraction of PGE. Hydrometallurgy 2020, 196, 105419. [CrossRef]

8. EFSA Panel on Food Additives and Nutrient Sources added to Food (ANS). Scientific Opinion on the re-evaluation of boric acid (E 284) and sodium tetraborate (borax) (E 285) as food additives. EFSA J. 2013, 11, 3407.

9. Kankala, R.K.; Liu, C.-G.; Yang, D.-Y.; Wang, S.-B.; Chen, A.-Z. Ultrasmall platinum nanoparticles enable deep tumor penetration and synergistic therapeutic abilities through free radical species-assisted catalysis to combat cancer multidrug resistance. Chem. Eng. J. 2020, 383, 123138. [CrossRef]

10. Lim, G.-H.; Yu, T.; Koh, T.; Lee, J.H.; Jeong, U.; Lim, B. Reduction by water for eco-friendly, capping agent-free synthesis of ultrasmall platinum nanocrystals. Chem. Phys. Lett. 2014, 595-596, 77-82. [CrossRef]

11. Zhang, L.Y.; Zhao, Z.L.; Li, C.M. Formic acid-reduced ultrasmall Pd nanocrystals on graphene to provide superior electocatalytic activity and stability toward formic acid oxidation. Nano Energy 2015, 11, 71-77. [CrossRef]

12. James, B.D.; Wallbridge, M.G.H. Metal Tetrahydroborates. In Progress in Inorganic Chemistry; John Wiley \& Sons, Inc.: Hoboken, NJ, USA, 1970; pp. 99-231.

13. Andrieux, J.; Demirci, U.B.; Hannauer, J.; Gervais, C.; Goutaudier, C.; Miele, P. Spontaneous hydrolysis of sodium borohydride in harsh conditions. Int. J. Hydrog. Energy 2011, 36, 224-233. [CrossRef]

14. Zhou, Y.; Fang, C.; Fang, Y.; Zhu, F.; Liu, H.; Ge, H. Hydrogen generation mechanism of BH4- spontaneous hydrolysis: A sight from ab initio calculation. Int. J. Hydrog. Energy 2016, 41, 22668-22676. [CrossRef]

15. Fawzy, A. Influence of copper(II) catalyst on the oxidation of L-histidine by platinum(IV) in alkaline medium: A kinetic and mechanistic study. Transit. Met. Chem. 2014, 39, 567-576. [CrossRef]

16. Zhang, Q.; Wu, Y.; Sun, X.; Ortega, J. Kinetics of Catalytic Hydrolysis of Stabilized Sodium Borohydride Solutions. Ind. Eng. Chem. Res. 2007, 46, 1120-1124. [CrossRef]

17. Shang, Y.; Chen, R. Hydrogen Storage via the Hydrolysis of NaBH4 Basic Solution: Optimization of NaBH4 Concentration. Energy Fuels 2006, 20, 2142-2148. [CrossRef]

18. Murray, P.; Koch, K.R.; van Eldik, R. Mechanism of tetrachloroplatinate(II) oxidation by hydrogen peroxide in hydrochloric acid solution. Dalton Trans. 2014, 43, 6308-6314. [CrossRef]

19. Cox, L.E.; Peters, D.G.; Wehry, E.L. Photoaquation of hexachloroplatinate (IV). J. Inorg. Nucl. Chem. 1972, 34, 297-305. [CrossRef]

20. Gamons, C.H. Experimental investigations of the hydrothermal geochemistry of platinum and palladium: V. Equilibria between platinum metal, Pt(II), and Pt (IV) chloride complexes at 25 to $300^{\circ} \mathrm{C}$. Geochim. Cosmochim. Acta 1996, 60, 1683-1694. [CrossRef] 
21. Finney, E.E.; Finke, R.G. Nanocluster nucleation and growth kinetic and mechanistic studies: A review emphasizing transitionmetal nanoclusters. J. Colloid Interface Sci. 2008, 317, 351-374. [CrossRef]

22. Finney, E.E.; Finke, R.G. Fitting and interpreting transition-metal nanocluster formation and other sigmoidal-appearing kinetic data: A more thorough testing of dispersive kinetic vs chemical-mechanism-based equations ans treatments for 4-step type kinetic data. Chem. Mater. 2009, 21, 4468-4479. [CrossRef]

23. Kytsya, A.; Bazylyak, L.; Hrynda, Y.; Horechyy, A.; Medvedevdkikh, Y. The Kinetic Rate Law for the Autocatalytic Growth of Citrate-Stabilized Silver Nanoparticles. Int. J. Chem. Kinet. 2015, 47, 351-360. [CrossRef]

24. Thanh, N.T.K.; Maclean, N.; Mahiddine, S. Mechanisms of Nucleation and Growth of Nanoparticles in Solution. Chem. Rev. 2014, 114, 7610-7630. [CrossRef]

25. Watzky, M.A.; Finke, R.G. Transition Metal Nanocluster Formation Kinetic and Mechanistic Studies. A New Mechanism When Hydrogen Is the Reductant: Slow, Continuous Nucleation and Fast Autocatalytic Surface Growth. J. Am. Chem. Soc. 1997, 119, 10382-10400. [CrossRef]

26. Watzky, M.A.; Finney, E.E.; Finke, R.G. Transition-Metal Nanocluster Size vs Formation Time and the Catalytically Effective Nucleus Number: A Mechanism-Based Treatment. J. Am. Chem. Soc. 2008, 130, 11959-11969. [CrossRef] [PubMed]

27. Wojnicki, M.; Fitzner, K.; Luty-Błocho, M. Kinetic studies of nucleation and growth of palladium nanoparticles. J. Colloid Interface Sci. 2016, 465, 190-199. [CrossRef] [PubMed]

28. Lente, G.; Fabian, I.; Poe, A.J. A common misconception about the Eyring equation. New J. Chem. 2005, 29, 759-760. [CrossRef]

29. Gupta, K.K.S.; Begum, B.A.; Pal, B. Kinetic behaviour and relative reactivities of some aldoses, amino sugars, and methylated sugars towards platinum(IV) in alkaline medium. Carbohydr. Res. 1998, 309, 303-310. [CrossRef]

30. Smirnov, S.; Vlassiouk, I.; Kutzki, O.; Wedel, M.; Montforts, F.-P. Unusual Role of Oxygen in Electron-Transfer Processes. J. Am. Chem. Soc. 2002, 124, 4212-4213. [CrossRef]

31. Pourzahedi, L.; Eckelman, M.J. Comparative life cycle assessment of silver nanoparticle synthesis routes. Environ. Sci. Nano 2015, 2, 361-369. [CrossRef]

32. Schweitzer, G.K.; Pesterfield, L.L. The Aqueous Chemistry of the Elements; Oxford University Press: Oxford, UK, 2010.

33. Barin, I.; Knacke, O.; Kubaschewski, O. Tables. In Thermochemical Properties of Inorganic Substances: Supplement; Barin, I., Knacke, O., Kubaschewski, O., Eds.; Springer Berlin Heidelberg: Berlin/Heidelberg, Germany, 1977; pp. 1-861. 